\title{
Postures in Therapeutic Education of Patient: A Paradigm Shift in Caregiver-Sick Person Relation? Dancot Jacinthe
}

Department of Nursing, Haute Ecole Robert Schuman, Belgium

\section{Abstract}

Background: A French law of 2009 made Therapeutic Education of Patient (TEP) mandatory in settings. This led to emerging new ways of practice. The TEP is often used in the context of chronic illness, which forces the sick persons to manage their care trajectories by themselves. TEP helps them to develop an active expertise, thanks to a personalized process based on an empathic approach. The introduction of TEP processes goes together with adaptations of the care relation. The objective of this article is to report the elements relative to the evolution of postures in nurse-sick person relation, emerged from a larger study on TEP.

Methods: We have opted for an approach of collaborative action research, with a qualitative methodology. Two series of comprehensive interviews were conducted at six months intervals, with several caregivers of hospital settings, sick persons, families, transversal workers in hospital, and external workers. This was accompanied by non-participative observations, collection of written prints of activity and focus groups. The results were obtained using thematic analysis.

Results: In their description of relation to caregivers, sick persons identify the following themes: status of subject, availability of caregivers, communication modalities, caregivers' characteristics influencing the relation.Caregivers identifies the themes of the posture in relation and of the working conditions.

Conclusions and discussion: For what concern nurses, sick person's report mainly a lack of physical or psychological availability, insufficient consideration for feelings, an absence of holistic view, a tendency to seize power. Regardless of its educative objectives, TEP is the opportunity for the caregiver to develop a qualitative relational dimension, based on a holistic conception of health and care and on an understanding of the complementarity of the role of both parties.

\section{Introduction}

This article focuses on elements related to the posture in caregiversick person relation. These elements emerge from a study on Therapeutic Education of Patient (TEP) and more specifically on the evolution of nurses' and sick persons' postures in the context of TEP implementation in French hospital settings.

\section{Background}

The French law« Hospital, Patient, Health and Territory » of 2009 made TEP mandatory in settings and marked out its use. This led toemerging new practices aiming to compliance and also to more individualized care and health paths, studied in a research program jointly conducted by the "Chaire de l'Institutd'Educationthérapeuti que de l'Université Pierre et Marie Curie " (Paris 6, France), by the "Centre de Recherchesur la Formation du Conservatoire national des Arts et Métiers »(CNAM-CRF, Paris, France) and by the " EcoleCentraleSupélec [1].

Introducing TEP often goes together with a significant reorganization of care structures and activities, and with new learning's for all actors which will lead to identity transformations. Understanding these transformations was the focus of the research program. This article will focus on the transformations of nurse-sick person relations.

\section{Theoretical frame}

A good understanding of what is at stake in these relations requires apprehending properly what are chronic illness, TEP and caregiversick person relation in the context of hospital settings in France.

\section{Chronicillness}

The World Health Organization [2] defines chronic illness as « a health problem needing several years care ». This wide open definition embraces many types of illness: contagious or not, physical or mental, or in generalany illness leading to anatomical and/or functional longlasting damages.

The Haute Autorité de Santé [3] orientates its definition of chronic illness in a public health perspective as being the presence of a longlasting pathological state of any nature (physical, psychological, cognitive), present since at least three months, impacting on daily life. Such impact can include functional limitation of activities or social participation, dependence on treatment, diet, equipment, physical or psychological support orany medico-social prevention.

Such long-lasting illness invades all spaces of life, forcing the sick persons to manage their care trajectories by themselves. This task is complicated, particularly in hospitals, by the compartmentalization of health system and the separation of health professionals according to their medical specialties [4], and by the resulting absence of holistic consideration of the chronically sick persons.

"Corresponding Author: Dr. Dancot Jacinthe, Departement of Nursing , Haute Ecole Robert Schuman, Belgium; E-mail: jacinthe.dancot@hers.be

Citation: Jacinthe D (2016) Postures in Therapeutic Education of Patient: A Paradigm Shift in Caregiver-Sick Person Relation?. Int J Nurs Clin Pract 3: 178. doi: http://dx.doi.org/10.15344/2394-4978/2016/178

Copyright: () 2016 Jacinthe. This is an open-access article distributed under the terms of the Creative Commons Attribution License, which permits unrestricted use, distribution, and reproduction in any medium, provided the original author and source are credited. 
The chronic illness imposes a long-lasting compliance, and the integration of its treatment and its consequences into daily life. The sick person needs thus time to accept and implement new behaviors: the so-called adhesion time [5-7]. The caregiver feels engaged in a race against time to prevent complications $[6,7]$. So are the temporalities divergent.

The relationship to time and the functioning of sick persons are furthermore modified by the consciousness of their own finiteness and the related permanent feeling of uncertainty.

\section{Therapeutic Education of Patient}

In 1996, WHO [8] defined TEP by its objective: train patients to manage themselves and adapt the treatment to their own chronic illness, enabling them to master the daily follow-up. Through enhancing efficient self-management and quality of long-lasting care, TEP contributes to the reduction of care costs for both patients and society.

WHO then underlined the need for interdisciplinary medical coordination and partnership with the patient, eased by his information and possibly his training, and the psychological support he receives. TEP was translated into rather standardized programs allowing the patient to live comfortably with his illness.

TEP since evolved to focus on helping the sick person to develop an active expertise: these approaches favor the integration of education to care and promote a personalized process based on an empathic approach $[9,10]$.

Promoting patient's autonomy is common to all TEP approaches. But what is new is the active role-played by the patient who is formally recognized as having the competences to design the care process jointly with the medical team.

\section{Caregiver-sickperson relation}

The therapeutic relation is recognized as being the basis of nursing care. It is a «deliberate relation, oriented towards a specific goal and aiming at the best interest of the patient and at the best possible evolution of his health [11].

This relation takes place in a particular context, with pre-established codes depending among others on the representations of the actors over their mutual roles in the process. The more these representations will diverge, the more the relation will be difficult to establish because of the differences in mutual expectations [12].

The caregiver-sick person relation is by nature asymmetrical (Sorsanna, 1999, quoted by [12]), particularly in hospitals, where patients must adapt to a micro culture, an organization, ways of communication, and to an environment which appear strange to them and which they do not master. One of the goals of caregivers is to restore symmetry [12] or at least reciprocity [13] in the relation. This may be done by taking a " deliberative " posture [13] in which the patient's autonomy is viewed as a process of moral self-development linked to his medical care. The patient is empowered to endorse, through discussion, the health-related values, their worthiness and their implications.

In order to empower the patient, the caregiver encourages him to develop the capacity to satisfy his health needs by himself and to mobilize the necessary resources so as to feel in control of his own life [14]. « A person is autonomized when he/she has enough knowledge to decide rationally, sufficient control and internal resources to implement his/her decisions, and the practical experience to assess the effectiveness of these decisions [14].

\section{Aim of the research}

As the sick person's role in therapeutic process evolves simultaneously with the one of other actors of care system, the caregiver-sick person relations and their evolutions will be studied in the context of hospital settings practices.

Our objectives are to understand the impact of TEP introduction on the interactions between caregivers and sick persons, and to explore the evolutions of the mutual perceptions of actors and the way they live these evolving relations.

In this article, we address the evolution of postures of caregiver and sick person.

\section{Methodology \\ Action research}

We have opted for an approach of collaborative action research. This approach builds on partnership among all actors to elaborate scientific knowledge at the heart of the action, while constantly adjusting it [15].

This is a qualitative methodology, aiming to understand subjective phenomenons and their links.

\section{Overall view of the study}

The empirical stage includes two series of comprehensive interviews (semi directive), at six to eight months intervals, conducted with several caregivers of hospital settings, sick persons, families, transversal workers in hospital, and external workers. The first series of interviews is enriched with non-participative observations in settings, with collection of written prints of activity and with focus groups.

After the first series of interviews, an analysis is presented to every setting during a steering committee, in order to validate the understanding of the current functioning, to trigger reflection on needed adjustments and to identify the themes which will be treated during the second series of interviews.

This process takes place in three hospitals in Paris and one hospital in Franche-Comté (France). In each hospital, one to three settings are integrated to the study, in addition to transversal or external actors of the TEP process.

The diversity of settings allows exploring various situations regarding TEP: some services have already a well anchored TEP approach, others are initiating this type of process, one still has presently no TEP project.

The interviews inside the settings allow a good understanding of subjective real-life experiences. The interviews of transversal or external actors give an overall understanding of the design flow of the patient support process. 
The sample size is function of its capacity to saturate the information. It represents 8 to 12 caregivers and 8 to 12 patients for each setting.

The interviews and focus groups data are treated by content or thematic analysis, following the three steps of categorization, description and theoretical explanation.

The theme of evolution of postures in the relation is especially explored in the interviews with nurses and patients.

If so wished, each hospital can have the study previously approved by an ethic committee. The presence of a sick expert in the research team contributes to ensure the respect of sick persons sensitivity during the interviews, and helps to focus the analysis on what is the most important for them, avoiding an excessive intellectualization disconnected from their real-life experience and feeling.

\section{Result and Discussion}

\section{Relation as viewed by sick persons in the first series of interviews}

Relation is influenced by the change of status lived by the patient during hospitalization: "When you enter the hospital, you are not the same person any more, you give up part of yourself to people whom you don't know».

In their description of relation to caregivers, sick persons identify the following themes: loss of status of subject (the sick person becomes a care object), insufficient availability of caregivers, diversity of communication modalities, caregivers' characteristics influencing the relation.

About the feeling of becoming a care object, patients indicate that the professionals establish a relation only when they find it interesting for their own tasks and that they limit the content of the interaction to these tasks. Once they have obtained what they need, the interaction stops. The nurse-patient relation is based on technical care in which the patient's body becomes an extension of medical material.

In the most extreme cases, patients do not know the identity of their caregiver's nor their professional qualification.

In the eyes of patients, caregiver's sometimes lack availability, be it time or psychological receptivity.

Communication is based on explanations, advices, control. There are only few questions about subjective real-life experience.

In terms of explanations, patients expect spontaneous and kindly delivered information. Some of them declare themselves satisfied, even though, according to our observations, they did not receive any real answer. Others complain about the necessity to question, sometimes repeatedly.

For some patients, not only do they have the right to be informed, but also to give their agreement: "The patient stays the master». This covers decisions on diagnosis and treatment but also on daily care: meals, schedule of care, use of a blanket in case of fever, etc.

Sometimes, patients note an inadequacy in the relation, particularly the taking into account of their feelings, especially by doctors. «Repeatedly, I state that they have studied cardiology but no psychology.
[...] They are not equipped for... they evacuated all this for the benefit of the technicality». The quoted patient thinks that nurses are more sensitive to his feelings: «More importantly, they hear what is not said».

Other patients identify a caregivers' seizure of power in the relation, through subtle attitudes like: using a childish or too scientific vocabulary, nurses coming in force to face an annoying patient, doctors asserting their qualification to make their decisions indisputable.

Other factors enhance the establishment of the relation, among which spatial proximity, time, psychological receptiveness, lack of fear.

In short, patients feel at ease in the relation with caregivers not as much for their professional qualification than for their capacity to listen, their availability and receptiveness.

The patient's entourage has also an important role in helping the sick person to understand medical information and to take health-related decisions. A close relative can give advice or even take decisions. Family's words can weigh more than those of caregivers. Families are also more involved in psychological support.

In conclusion, from the sick person's point of view, the quality of caregiver-sick person relation is experienced as extremely important, is it for obtaining information's, feeling supported or simply feeling considered as a human and implicated person. Expectations differ depending on the caregiver's nature: information's are mainly expected from doctors, listening and support from nurses. The most influencing factor seems to be the professional's posture in the interaction.

Often, the relation is judged insufficient. Reasons can be lack of time, lack of psychological receptiveness, lack of communication skills. Furthermore, a caregiver showing few or no wish to implicate the sick person -notwithstanding to collect his agreement - instills a patient's feeling of reification.

Communication gaps can be, at least partially, counterbalanced by the support of close relatives.

\section{Relation as viewed by caregivers}

Practicing TEP can lead the caregiver to re-examine his/her position in the care relation. Instead of limiting the interaction to the current act, TEP requires successive interactions, the continuity of which allows the development of the relation [12]. To take into account the knowledge, capacities, values, wishes and needs of the patient, allows to break the natural asymmetry of caregiver-sick person relation, and to restore a level of mutuality $[12,13]$. The objective is not simply the realization of a care act, as a finished product supplied by the caregiver, but is also the amplification, as far as possible, of the patient's power on his own life and, in particular, on his health trajectory : in short, to "autonomize" him [14]. A long time is required to build this care relation, which is the basis of the development of the TEP process.

A repetitive and fragmented care organization is deeply incompatible with the nurses' holistic conception of care. The difficulty they have to devote time as they would like to the care of patients, leaves them strongly frustrated and increases their stress. They claim that they are not able to think about quality of care, and that they have to limit their ambition to simply achieve strictly essential acts: «Quality, forget about it, we are already happy if we are able to ensure a minimal level of safety". 
The important psychological load caused by these working conditions is an obstacle to the psycho-affective mobilization required for an empathic attitude towards patients. In addition to the frustration comes the fear of misconduct: «A day will come when, because of stress, we will make a mistake, it is unavoidable».

The experience of TEP-trained caregivers confirms it. Once they became conscious of the worthiness of the holistic view allowed by a therapeutic relation, the perspective of coming back to a functional care as it prevails in conventional settings becomes unsustainable. A similar discomfort affects doctors who support TEP principles: they receive criticisms from colleagues whose more traditional care practices are less well received.

Besides education about treatment, TEP is perceived as effective in developing a confidence climate, which means: to be perceived by the patient as a person of confidence, referent for his/her health path ; and also, to feel confident that the sick person is capable to manage his/her illness, and to be able to transmit this feeling. It is the quality of the relation which has been initiated by the TEP process, which is underlined by nurses as critical to establish this climate.

\section{Conclusion and Avenues for Practice, Management, Education and Research}

Sick persons identify missing elements in the relations usually maintained with caregivers. More specifically for what concern nurses, they reported mainly a lack of physical or psychological availability, insufficient consideration for feelings, an absence of holistic view, a tendency to seize power, etc.

Regardless of its educative objectives, TEP is the opportunity for the caregiver to develop a qualitative relational dimension, based on a holistic conception of health and care and on an understanding of the complementarily of the role of both parties, what requires to autonomize the sick person.

It is difficult to determine which the causal factor is: is it a different conception of relation that leads some caregivers to TEP, or is it their discovery of TEP that leads them to a new conception of the relational dimension of care?

Whatever the answer, it looks obvious that TEP practice induces a posture change in relation: for the patient, led to professionalize himself as sick person, as well as for the caregiver. This change could be viewed as a revolutionary new care paradigm, but nurses can see it more like a return to the roots, the fundamentals of relation as studied during their initial education but faded away in a working context making them impracticable.

These conclusions have implications on clinical practice: they show the importance, for nurses, to rethink their posture if they want to develop an optimal relational dimension, allowing to ensure qualitative care and to thrive on their work. TEP projects can help achieve this.

Managers are also invited to rethink the care organization in order to allow a holistic care giving room to the caregiver-sick person relation. Reflection on care pathway should also be developed, in particular to reconcile the organizational temporalities of settings and institutions with the individual temporality of sick persons.
Nursing teachers should further develop knowledge on caregiversick person relation and increase posture training, through activities of self-development and emotional management.

Lastly, we identify some research gaps. Among others, research should further explore the knowledge, know-how and attitudes developed by settings during their TEP practice and, more widely, about caregiver-sick person relation. A particular attention should be given to the implications for the working organization modalities on this relation.

\section{Competing Interests}

The authors have no competing interests with the work presented in this study.

\section{References}

1. Obertelli P, Pouteau C, Haberey-Knuessi V, Dancot J, Roux LA, et al (2015) Evolution des relations soignants-malades au regard des pratiques d'éducation thérapeutique. Rapport de recherche. CRF-CNAM, Ecole Centrale Supélec.

2. Rat AC (2004) La maladie chronique.In Direction Générale de la Santé, Santé publique, qualité de vie et maladies chroniques : attentes des patients et des professionnels11-15.

3. Agrignier N, Rat A-C (2010) Quelles définitions pour la maladie chronique ? ADSP. 72: 12-14

4. Briançon S, Guérin G, Sandrin-Berthon B (2010) Les maladies chroniques ADSP. 72: 11.

5. Abelhauser A, Levy A, Laska F (2013) Le temps de l'adhésion. Document non publié.

6. Assal JP (1997) Traitement des maladies de longue durée : de la phase aiguë au stade de la chronicité. Une autre gestion de la maladie, un autre processus de la prise en charge 16

7. Grimaldi A (2006) La maladie chronique. Les tribunes de la santé 13: 45-51.

8. Haute Autorité de Santé (HAS) (2007) Education thérapeutique du patient. Définition, finalités, organisation. Recommandations. France: HAS.

9. Sandrin-Berthon B (2010) Diagnostic éducatif ou bilan éducatif partagé ? Médecine des maladies métaboliques. 4: 38-43.

10. Tourette-Turgis C (2008) L'activité de maintien de soi en vie et son accompagnement : un nouveau champ de recherche en éducation Paris: CNAM/Université Paris

11. Registered Nurses Association of Ontario (2002) Etablissement de la relation thérapeutique. Lignes directrices sur les pratiques exemplaires en soins infirmiers. Ontario : RNAO.

12. Formarier $M(2007)$ [The caring relationship, concepts and conclusions]. See comment in PubMed Commons below Rech Soins Infirm : 33-42.

13. Emanuel EJ, Emanue LL (1992) Four models of the physician-patient relationship. See comment in PubMed Commons below JAMA 267: 22212226.

14. Gagnon J (2009) Empowerment. In: Les concepts en sciences infirmières. Lyon: Mallet Conseil 11: 162-165.

15. Liu M (1997) Fondements et pratiques de la recherche-action. Paris: L'Harmattan. 